\title{
AERODYNAMIC AND AEROELASTIC PERFORMANCE OF AN IRREGULAR BRIDGE TOWER: A CASE STUDY
}

\author{
Bin-hua Xia, ${ }^{*}$ Zeng-shun Chen, ${ }^{* *}$ Tian-long Li, ${ }^{*}$ Yong-da Yang, ${ }^{*}$ and Lei Liu***,****
}

\begin{abstract}
In this paper, the aerodynamic and aeroelastic performance of the bridge tower of the Hong Kong-Zhuhai-Macao Bridge were investigated experimentally. The aerodynamic forces of the bridge tower were evaluated by using five-segment wind tunnel test models. The wind-induced dynamic response of the bridge tower in the alongwind, cross-wind, and torsional directions were tested by using an aeroelastic test model. From the wind tunnel tests, the drag, lift, and torsional force coefficients under different wind attack angles were observed and analysed. The aeroelastic phenomenon (i.e. galloping, vortex shedding) of the irregular bridge tower was evaluated. The most unfavourable case of wind-induced vibrations was analysed and checked. This study provides a way to evaluate aerodynamic and aeroelastic performance of an irregular bridge tower, and advances our understanding of the performance of the bridge tower.
\end{abstract}

\section{Key Words}

Irregular bridge tower, wind tunnel test, aerodynamic performance, aeroelastic performance

\section{Introduction}

With the development of economy and society, long-span bridges and high-rise buildings have been widely built [1], [2]. To evaluate the aerodynamic and aeroelastic performances of the bridges and buildings, a wind tunnel test is accepted as an effective way. Static measurements, i.e. high-frequency base balance (HFBB) test technique and synchronous multi-pressure sensing system (SMPSS) test, are usually carried out to evaluate wind loads of structures [3]. The HFBB technique is accepted as an

* School of Civil Engineering and Architecture, Changsha University of Science and Technology, Changsha 410014, People's Republic of China; e-mail: \{19482165, 29196397, allove4201\}@163.com

** Key Laboratory of Bridge Structure Engineering Transportation Industry (Chongqing Jiaotong University), Chongqing, People's Republic of China; e-mail: chenzs2007@163.com

*** China Communications construction company Ltd., Beijing, People's Republic of China; e-mail: liuleill@vip.sina.com

**** School of Civil Engineering, Tongji University, Shanghai, People's Republic of China Corresponding author: Zengshun Chen

Recommended by Prof. Chaomin Luo

(DOI: 10.2316/Journal.206.2017.6.206-5126) economical and expeditious alternative to the more involved SMPSS. It was developed by Tschanz [4] and is now widely used for wind load studies [5]-[7]. The technique involves the base force measurements of a nearly rigid scale model, which models only the external geometry of the structure. Based on the observed base force, using time or frequency domain analysis, the response of structures can be predicted [8]. Another effective way to evaluate the aeroelastic performance of structures is an aeroelastic test technique [9], [10]. From the HFBB and aeroelastic test, the wind effect on structures could be evaluated and utilized for designing engineering structures.

However, many structures were built with nonprismatic and irregular geometries not only for artistic appearance but for reasonable loading-bearing considerations. The shape of the bridges and buildings may make them more sensitive to wind excitation than those with a regular shape. Wind effect on these irregular structures should be well concerned. Cluni et al. [3] investigated wind action on regular and irregular tall buildings in a boundary wind tunnel. Both the HFBB and SMPSS wind tunnel tests were performed to compare the aerodynamic characteristics of the regular building with the irregular one. Chan et al. [11] investigated integrated wind load analysis and stiffness optimization of irregular tall buildings with three-dimensional modes by using the HFBB test technique. Vaz et al. [12] improved the aerodynamic performance of irregular bridge deck sections with different configurations (i.e. "H" and "A" shapes) and under different wind attack angles by using wind tunnel test models. Many other studies have also focussed on the aerodynamic performance of structures with different geometrics using HFBB or SMPSS wind tunnel test techniques [13], [14]. Meaningful results have been obtained, which can be utilized for design of irregular structures.

However, the wind effect on structures is complicated and is different with different configurations. Also, the wind effect on structures in the cross-wind direction has not been fully understood. For example, in the crosswind direction, the response of structures may be affected by turbulence, wake-excitation, and fluid-structure interaction [10], [15]-[17], which make oscillations in this direction complicated. In this direction, structures mainly 


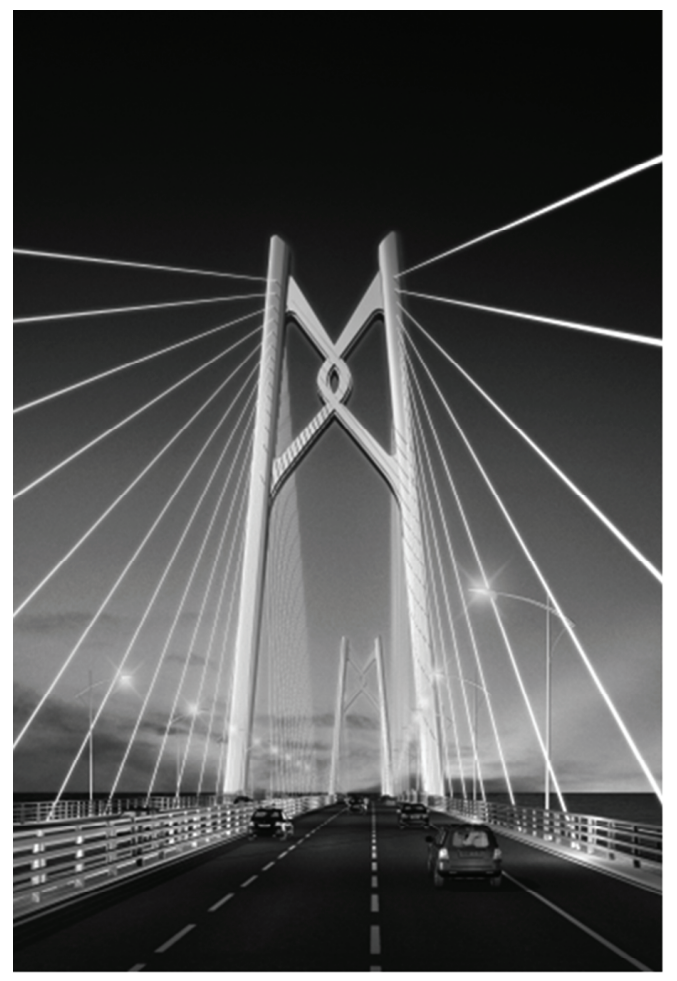

(a)

Figure 1. The bridge tower of the Qingzhou Channel Bridge: (units: $\mathrm{cm}$ ).

suffer aeroelastic phenomena of buffeting, vortex-induced vibration (VIV), and galloping. Buffeting of structures is characterized random oscillation which is due to wind turbulence [18]. Unsteady flow over bluff bodies may generate a regular pattern of vortices which is called a vortex street. The vortices interact with the bluff bodies and provide the source of the effect called VIV [19]. Galloping is characterized large oscillations and depends on the motion of structures. VIV and galloping are relative large oscillations, which may lead to fatiguing or collapse of structures, and they have to be taken into account when evaluating the performance of structures under the action of wind.

The present study aims to carry out wind tunnel tests to evaluate the aerodynamic and aeroelastic performance of a bridge tower with irregular "Chinese knot" shape. The study has been carried out during the bridge tower's design stage to provide assistance in that process. The HFBB wind tunnel test with five-segment test models and aeroelastic wind tunnel test were carried out to evaluate the wind load and response of the bridge tower. The test results were obtained and analysed. This study gives a way to evaluate the wind load and response of an irregular bridge tower (i.e. the aerodynamic force was evaluated by five-segment models), and advances the understanding of wind effects on the bridge tower.

\section{Wind Tunnel Test Models}

\subsection{Description of the Prototype}

The Qingzhou Channel Bridge is across-sea cable-stayed bridge and an important part of the HongKong-ZhuhaiMacao Bridge. It is located at the tropical monsoon
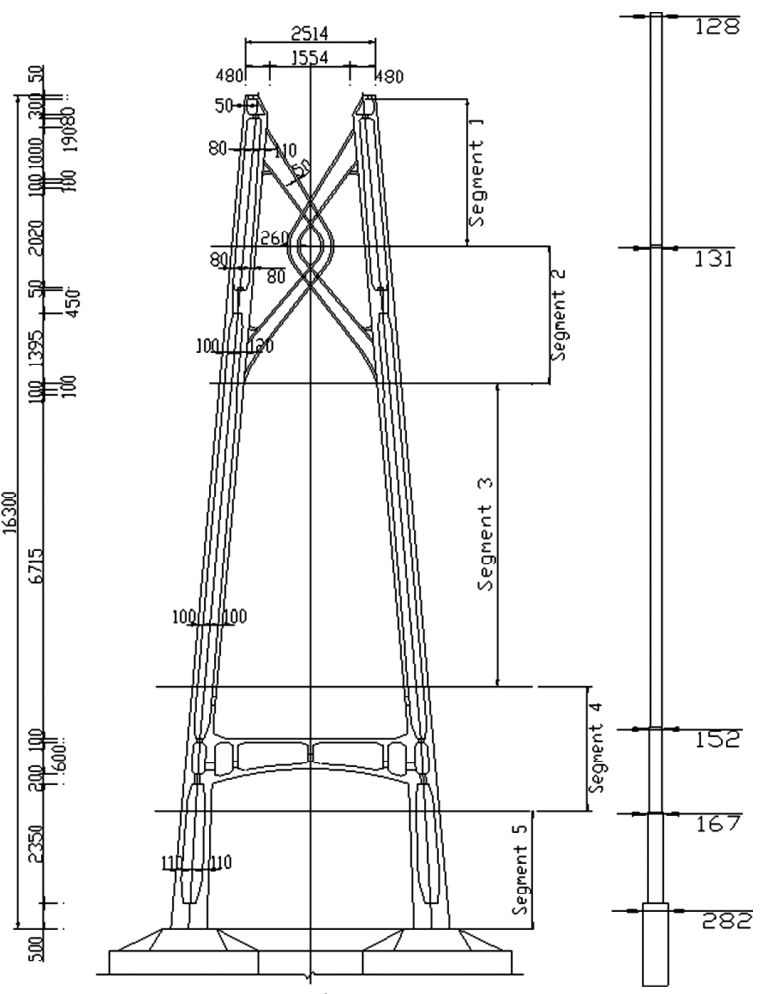

(b)

(a) Simulated diagram and (b) Dimensions of the tower climate region of the South Asia, which is frequently affected by the disastrous weather and strong wind. The overall length of the bridge is $1,150 \mathrm{~m}$ and the span arrangement is $(110+236+458+236+110) \mathrm{m}$. The height of bridge tower is around $163 \mathrm{~m}$. The tower is mainly made of concrete and a box-shaped section is utilized. The appearance of the tower is designed as "Chinese knot".

\subsection{Aerodynamic Force Test Model}

The aerodynamic force measurement of the bridge tower was carried out in the TJ-2 section of the wind tunnel at Tongji University. A rigid model with a scale ratio of 1:20 of the prototype (Fig. 1) of the tower was utilized. The dimension of the wind tunnel is $15 \mathrm{~m}$ (length) $\times 3.0 \mathrm{~m}$ (width) $\times 2.5 \mathrm{~m}$ (height). The maximum wind speed is $68 \mathrm{~m} / \mathrm{s}$ and the minimum is $2 \mathrm{~m} / \mathrm{s}$. The test was performed in smooth wind flow. It should be noted that the 1:20 test model of the bridge tower is relatively large to the dimension of the wind tunnel. To solve this problem, the test model is divided into five segments (Figs. 1 and 2), and each segment was tested under the same conditions. The drag, lift, and torsional force coefficients of the segments, under different wind attack angles $\left(0^{\circ}, 2^{\circ}, 5^{\circ}, 10^{\circ}, 15^{\circ}\right.$, $\left.30^{\circ}, 45^{\circ}, 60^{\circ}, 75^{\circ}, 80^{\circ}, 85^{\circ}, 90^{\circ}\right)$, were observed using an HFBB test technique.

\subsection{Aeroelastic Test Model}

It is complicated to perform the aeroelastic test of the bridge tower. The model of the tower should be well made and some physical parameters (i.e. Froude number, Strouhal number, damping ratio, density ratio, etc.) 

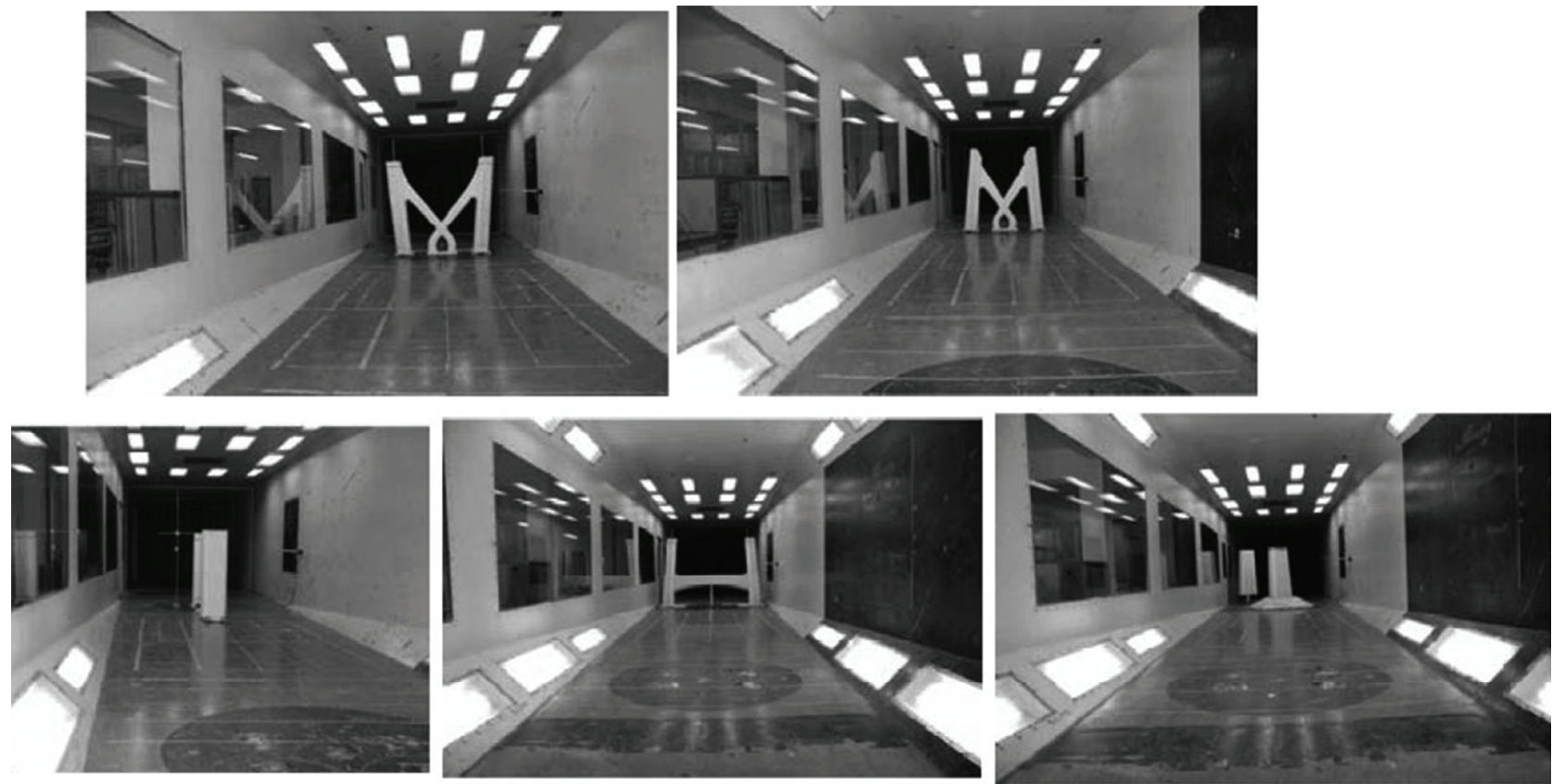

Figure 2. The wind tunnel test models divided into five segments.

Table 1

Parameters of the Test Model of the Bridge Tower

\begin{tabular}{|l|c|c|c|}
\hline Parameter & Units & Ratio & Remark \\
\hline Dimensions & $\mathrm{m}$ & $1: 80$ & Scale ratio \\
\hline Velocity & $\mathrm{m} / \mathrm{s}$ & $1: \sqrt{80}$ & Froude number \\
\hline Frequency & $\mathrm{Hz}$ & $\sqrt{80}: 1$ & Strouhal number \\
\hline Time & $\mathrm{s}$ & $1: \sqrt{80}$ & Strouhal number \\
\hline Unit mass & $\mathrm{kg} / \mathrm{m}$ & $1: 80^{2}$ & - \\
\hline Unit mass moment of inertia & $\mathrm{kg} \mathrm{m}^{2} / \mathrm{m}$ & $1: 80^{4}$ & - \\
\hline Bending stiffness & $E I$ & $1: 179^{5}$ & - \\
\hline Torsional stiffness & $G J_{d}$ & $1: 80^{5}$ & - \\
\hline Axial stiffness & $E A$ & $1: 80^{3}$ & - \\
\hline Damping ratio & $\zeta$ & 1 & Constant \\
\hline
\end{tabular}

should be strictly met. A scale ratio of 1:80 test model was selected to simulate the aeroelastic characteristics of the bridge tower. Correspondingly, other ratios are obtained and listed in Table 1.

The aeroelastic test was carried out in the TJ-2 section of the wind tunnel at Tongji University. The wind profile is simulated from the on-site measured parameters and it is directly given as $U_{z} / U_{10}=(Z / 10)^{0.098}$. The turbulence ranged from $20 \%$ to $7 \%$ along the height of the test model (Fig. 3). The test under smooth flow was also carried out. The fundamental frequency of the prototype, the test model of the bridge tower, and the damping ratios are listed in Table 2. Table 2 shows the maximum error between the prototype and the test model to be $4.4 \%$. It suggests that the dynamic characteristics of the bridge tower was well simulated. Then, the aeroelastic phenomena including buffeting, VIV, and galloping under different wind attack angles $\left(0^{\circ}-90^{\circ}\right.$ with an interval of $5^{\circ}$ and different wind velocities $(0-7.5 \mathrm{~m} / \mathrm{s})$ were observed (Fig. 4).

\section{Aerodynamic Force of the Bridge Tower}

The definitions for the aerodynamic force of the bridge tower are shown in Fig. 5. Correspondingly, the drag, lift and lift-moment force coefficients are defined as follows:

$C_{H}=\frac{F_{H}}{1 / 2 \rho V^{2} H}, \quad C_{V}=\frac{F_{V}}{1 / 2 \rho V^{2} H}, \quad C_{M}=\frac{M_{z}}{1 / 2 \rho V^{2} H^{2}}$ 
where $C_{H}, C_{V}$ and $C_{M}$ denote drag, lift, and lift-moment force coefficients in the wind coordinate axis (Fig. 5); $F_{H}$, $F_{V}$ and $M_{z}$ are drag, lift, and lift-moment forces in the wind coordinate axis (Fig. 5); $\rho$ is the air density, which is equal to $1.225 \mathrm{~kg} / \mathrm{m}^{3} ; H$ is the projection width of each segment model. $V$ is the wind velocity.
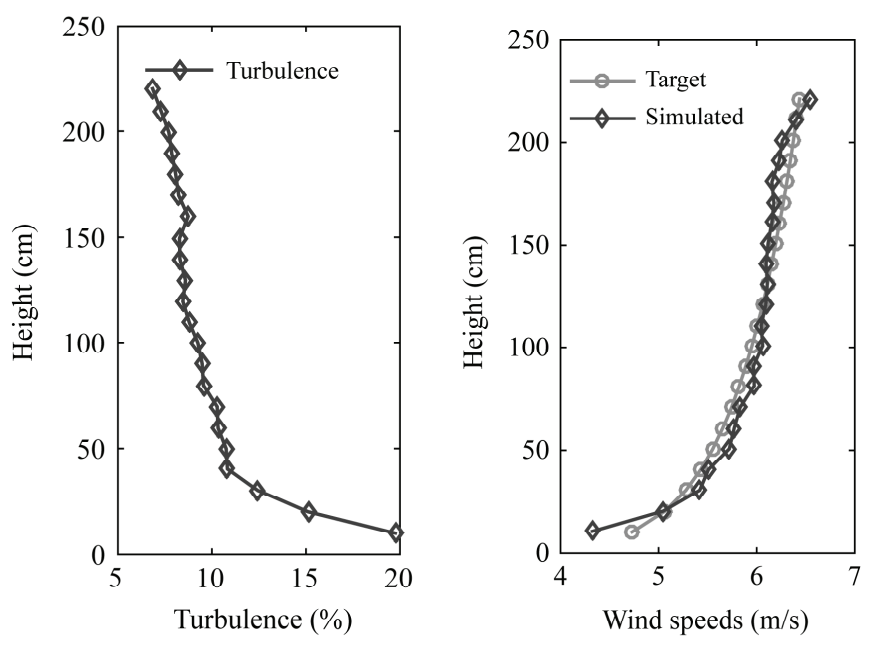

Figure 3. Simulated wind profile.

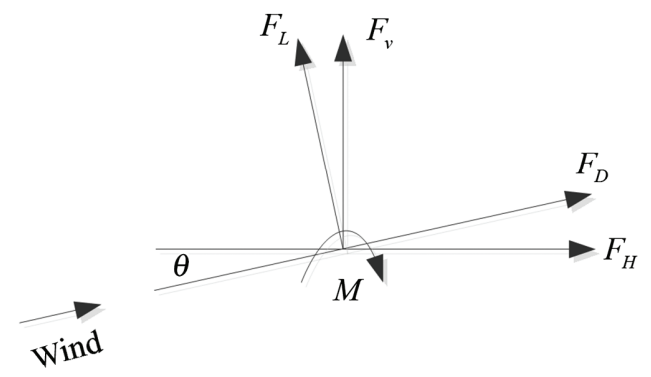

Figure 5. Definitions of aerodynamic force coefficients: drag, lift and torsional force coefficients.

Based on Fig. 4, the relationships of drag and lift forces in different coordinate systems are presented as follows:

$$
\begin{gathered}
F_{D}=F_{H} \cos (\theta)+F_{V} \sin (\theta) \\
F_{L}=-F_{H} \sin (\theta)+F_{V} \cos (\theta)
\end{gathered}
$$

where $F_{D}$ and $F_{L}$ are drag and lift forces in the body coordinate axis, respectively. $\theta$ is the wind attack angle.

From the force measurement (Section 2.2), the drag force, lift force, and torsional force coefficients of the bridge

Table 2

Dynamic Characteristics of the Prototype and the Test Model of the Bridge Tower

\begin{tabular}{|l|c|c|c|c|c|}
\hline First-order Mode & $\begin{array}{c}\text { Frequency } \\
\text { (Prototype) } \\
(\mathrm{Hz})\end{array}$ & $\begin{array}{c}\text { Frequency } \\
\text { (Model Required) } \\
(\mathrm{Hz})\end{array}$ & $\begin{array}{c}\text { Frequency } \\
\text { (Model Simulated }) \\
(\mathrm{Hz})\end{array}$ & $\begin{array}{c}\text { Error } \\
(\%)\end{array}$ & $\begin{array}{c}\text { Damping } \\
\text { Ratio (\%) }\end{array}$ \\
\hline $\begin{array}{l}\text { Along the bridge } \\
\text { direction }\end{array}$ & 0.2049 & 1.8325 & 1.7577 & 4.40 & 0.84 \\
\hline Cross the bridge direction & 0.5091 & 4.5536 & 4.6873 & 2.82 & 1.40 \\
\hline Torsional direction & 0.8589 & 7.6823 & 7.6168 & 1.59 & 1.20 \\
\hline
\end{tabular}

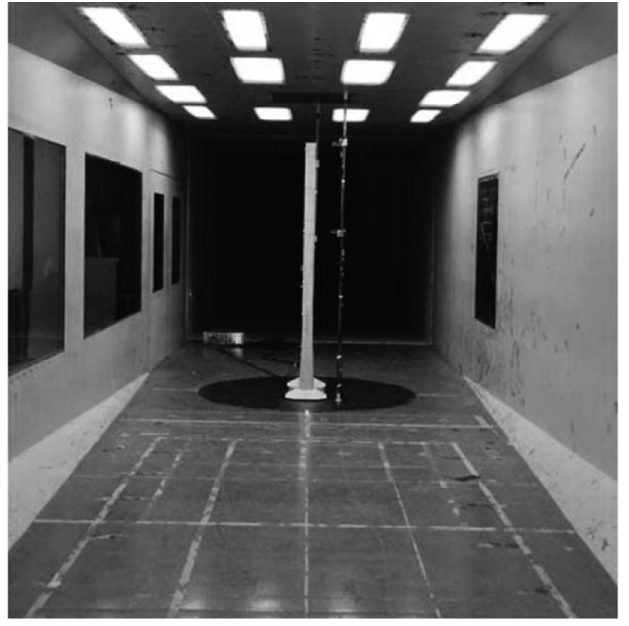

(a)

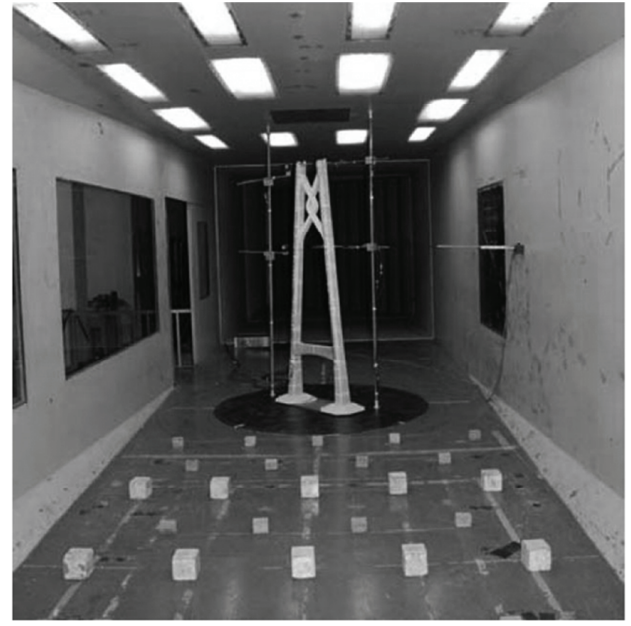

(b)

Figure 4. The aeroelastic wind tunnel test models: (a) The test model in smooth flow and (b) The test model in turbulent flow. 


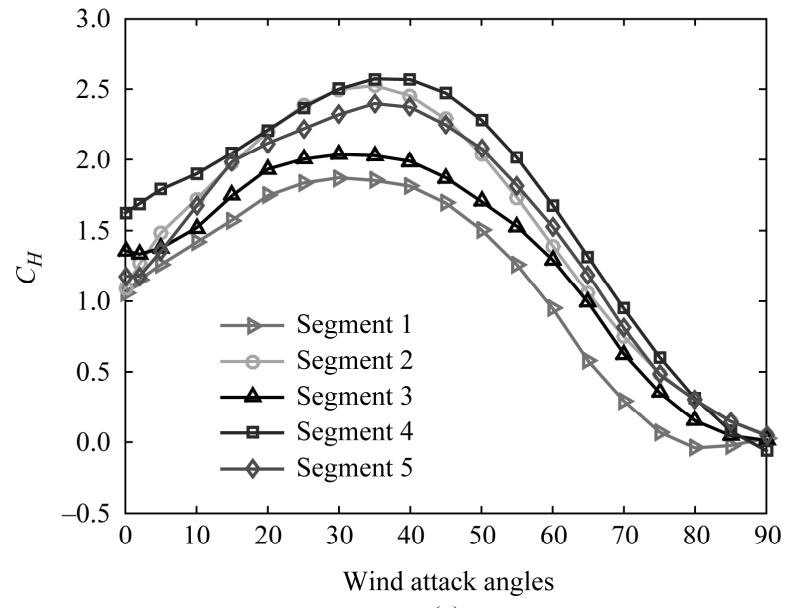

(a)

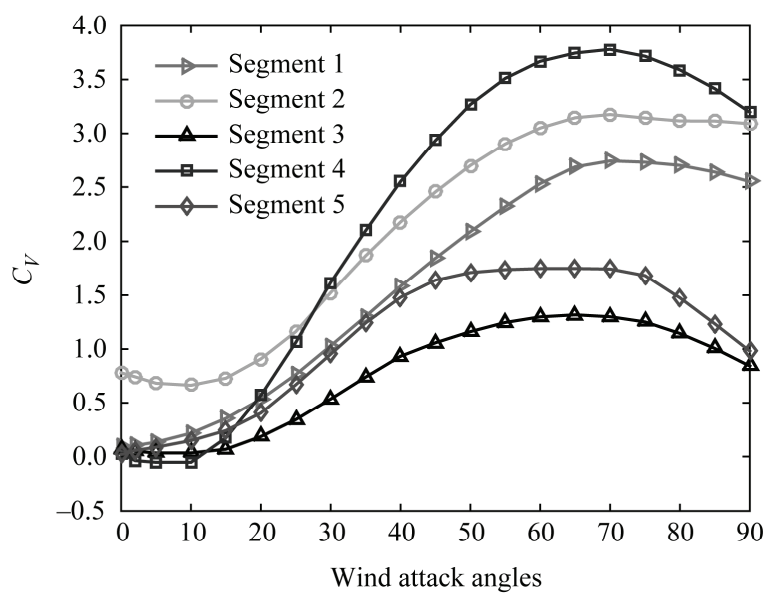

(b)

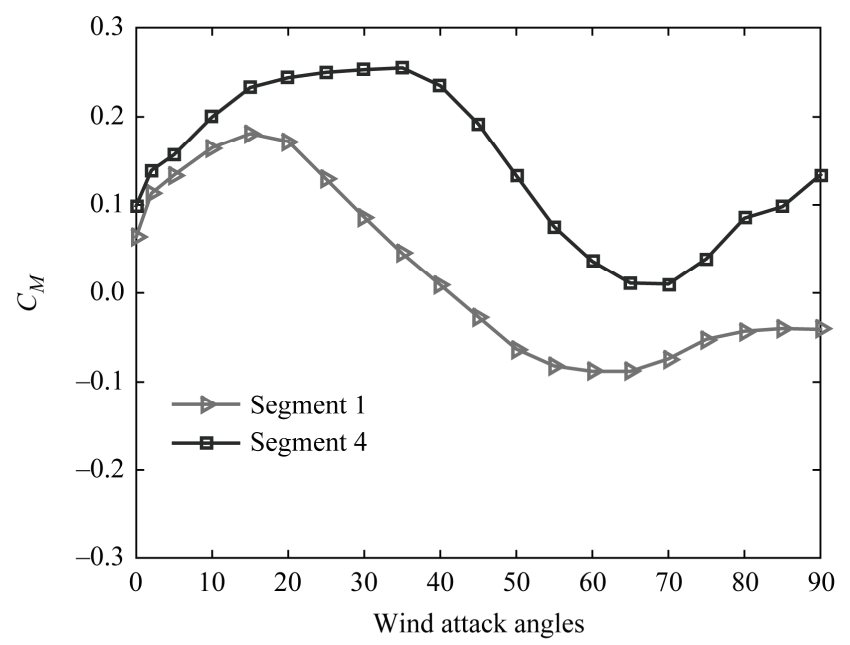

(c)

Figure 6. Aerodynamic force coefficients: (a) Drag force coefficients; (b) Lift force coefficients; and (c) Lift-moment force coefficients.

tower under different wind attack angles are obtained (Fig. 6). It should be noted that segments 3 and 5 are separated, and only segments 1,2 , and 4 exist torsional forces (herein, only the torsional forces of segments 1 and 4 are presented).

In Fig. 6, the magnitudes of the force coefficients are different, but the trends are in close agreement with each other. This suggests that the method for the force measurement of the bridge tower is reasonable. The maximum drag and lift coefficients occur on segment 4 , at the wind attack angles of $35^{\circ}$ and $65^{\circ}$, respectively. For the torsional force coefficient, the coefficients of segment 4 under different wind attack angles are positive and peaks occur at the wind attack angles of $35^{\circ}$ and $65^{\circ}$. The values of the torsional coefficients of segment 1 change from positive to negative at the wind attack angle of $40^{\circ}$. Besides, the maximum lift force coefficients are much larger than the maximum drag or torsional force coefficients. The results are very complicated and may be affected by many factors, i.e. the height and geometries of the test models, the different turbulence intensities along the height of the models, the end effect, etc. To give a detailed explanation, wind force characteristics along the height of each model should be acquired. Unfortunately, in this case study, only the base forces of the models were measured. The measured results advance the understanding of wind loads of irregular structures, which can be utilized to evaluate wind-induced responses of structures and are concerned by engineers.

\section{Aeroelastic Response of the Bridge Tower}

\subsection{The Design Wind Speed}

It should be noted that the wind speed in the construction stage of the Qingzhou Bridge is $39.1 \mathrm{~m} / \mathrm{s}$, which is obtained from meteorological observation (average time slot: $10 \mathrm{~min}$, return period: 30 years, height: $10 \mathrm{~m}$ ). Then, the design wind speed of the bridge tower in the construction stage is determined based on the Wind-Resistant Design Specification for Highway Bridges [20]

$$
\begin{aligned}
V_{d} & =\left(z / z_{10}\right)^{0.098} \cdot V_{10}=(167 \times 0.65 / 10)^{0.098} \cdot \\
& =49.4 \mathrm{~m} / \mathrm{s}
\end{aligned}
$$


Table 3

The Maximum Response of the Bridge Tower in the Turbulent Flow Condition

\begin{tabular}{|l|c|c|c|c|c|c|}
\hline \multirow{2}{*}{ Conditions } & \multicolumn{3}{|l|}{ Tip Amplitudes of the Tower } & \multicolumn{3}{|c|}{ Amplitudes at the 65\% Height of the Tower } \\
\cline { 2 - 7 } & $\begin{array}{c}\text { Along-bridge } \\
\text { Direction }\end{array}$ & $\begin{array}{c}\text { Cross-bridge } \\
\text { Direction }\end{array}$ & $\begin{array}{c}\text { Torsional } \\
\text { Direction }\end{array}$ & $\begin{array}{c}\text { Along-bridge } \\
\text { Direction }\end{array}$ & $\begin{array}{c}\text { Cross-bridge } \\
\text { Direction }\end{array}$ & $\begin{array}{c}\text { Torsional } \\
\text { Direction }\end{array}$ \\
\hline $\begin{array}{l}\text { Maximum } \\
\text { amplitude }\end{array}$ & $30.95 \mathrm{~cm}$ & $6.88 \mathrm{~cm}$ & $0.203^{\circ}$ & $14.35 \mathrm{~cm}$ & $3.40 \mathrm{~cm}$ & $0.050^{\circ}$ \\
\hline $\begin{array}{l}\text { Wind attack } \\
\text { angle }\end{array}$ & $85^{\circ}$ & $50^{\circ}$ & $90^{\circ}$ & $85^{\circ}$ & $50^{\circ}$ & $90^{\circ}$ \\
\hline
\end{tabular}

Table 4

The Maximum Response of the Bridge Tower in the Smooth Flow Condition

\begin{tabular}{|l|c|c|c|c|c|c|}
\hline \multirow{2}{*}{ Conditions } & \multicolumn{3}{|c|}{ Tip Amplitudes of the Tower } & \multicolumn{2}{|c|}{ Amplitudes at the 65\% Height of the Tower } \\
\cline { 2 - 7 } & $\begin{array}{c}\text { Along-bridge } \\
\text { Direction }\end{array}$ & $\begin{array}{c}\text { Cross-bridge } \\
\text { Direction }\end{array}$ & $\begin{array}{c}\text { Torsional } \\
\text { Direction }\end{array}$ & $\begin{array}{c}\text { Along-bridge } \\
\text { Direction }\end{array}$ & $\begin{array}{c}\text { Cross-bridge } \\
\text { Direction }\end{array}$ & $\begin{array}{c}\text { Torsional } \\
\text { Direction }\end{array}$ \\
\hline $\begin{array}{l}\text { Maximum } \\
\text { amplitude }\end{array}$ & $23.82 \mathrm{~cm}$ & $6.88 \mathrm{~cm}$ & $0.219^{\circ}$ & $10.42 \mathrm{~cm}$ & $3.33 \mathrm{~cm}$ & $0.055^{\circ}$ \\
\hline $\begin{array}{l}\text { Wind attack } \\
\text { angle }\end{array}$ & $70^{\circ}$ & $50^{\circ}$ & $50^{\circ}$ & $70^{\circ}$ & $50^{\circ}$ & $50^{\circ}$ \\
\hline
\end{tabular}

where $V_{d}$ is design wind speed of the bridge tower, $z$ is the $65 \%$ height of the bridge tower, $z_{10}=10 \mathrm{~m}, V_{10}=39.1 \mathrm{~m} / \mathrm{s}$.

Correspondingly, the galloping wind speed of the bridge tower is determined below:

$$
V_{c g} \geq 1.2 V_{d}=59.3 \mathrm{~m} / \mathrm{s}
$$

where $V_{c g}$ is the critical galloping wind speed of the bridge tower.

\subsection{The Most Unfavorable Case of the Response of the Bridge Tower}

From the aeroelastic measurement (Section 2.3), at the design wind speed of $49.4 \mathrm{~m} / \mathrm{s}$, the most unfavorable cases in turbulent and smooth flow conditions are listed in Tables 3 and 4 , respectively.

From Tables 3 and 4 , the maximum case is largely affected by the turbulence intensity in the along-bridge direction, and larger turbulence intensity tends to result in larger response. In the cross-bridge and torsional directions, the effect of turbulence intensity on the magnitudes of responses is slight, but the corresponding wind attack angles are largely affected. Furthermore, the responses of the bridge tower in the along-bridge direction are larger than those in the cross-bridge direction. This may be ascribed to different stiffness and dynamic characteristics (i.e. damping ratio, frequency) in different directions. Besides, the responses are larger at the tip end of the bridge tower than that at the $0.65 \mathrm{H}$ of the tower. It should be clarified that the design wind speed is determined from $0.65 \mathrm{H}$ of the bridge tower. Therefore, the results at $0.65 \mathrm{H}$ are also observed.
The responses of the bridge tower under different wind attack angles and wind speeds of each unfavorable case, which is determined in Tables 3 and 4 , are presented in Figs. 7-9.

In Figs. 7-9, the response of the bridge tower increases significantly with wind velocity in the along the bridge direction, and turbulence tends to increase the response largely (the maximum difference between the turbulent and smooth cases is 30\%). However, in the torsional direction, turbulence tends to decrease the response, but the magnitudes are small (the maximum difference between the turbulent and smooth cases is below 14\%). It is interesting that opposite trends are observed in the cross the bridge direction: at the tip end of the bridge tower, turbulence tends to decrease the response of the tower while it tends to increase the response of the tower at the height of $0.65 \mathrm{H}$. This may be ascribed to the end effect of the bridge tower and may also be affected by different turbulence intensities along the height of the bridge tower. Figures 7-9 also show that the most unfavourable case is that in the along the bridge direction, and it is largely affected by wind velocity and turbulent intensity.

\subsection{Vortex-induced Vibration of the Bridge Tower}

Slender structures mainly suffer from aeroelastic phenomena of buffeting, VIV, flutter, and galloping. Buffeting is characterized random oscillation which is due to wind turbulence [18]. Flutter and galloping are characterized large oscillations and depend on the motion of structures. Although the response of VIV is not as dangerous as flutter or galloping, it can influence the fruition and the fatigue life of a bridge deck [21]-[23]. Therefore, the galloping and VIV should be well considered for the design of the 

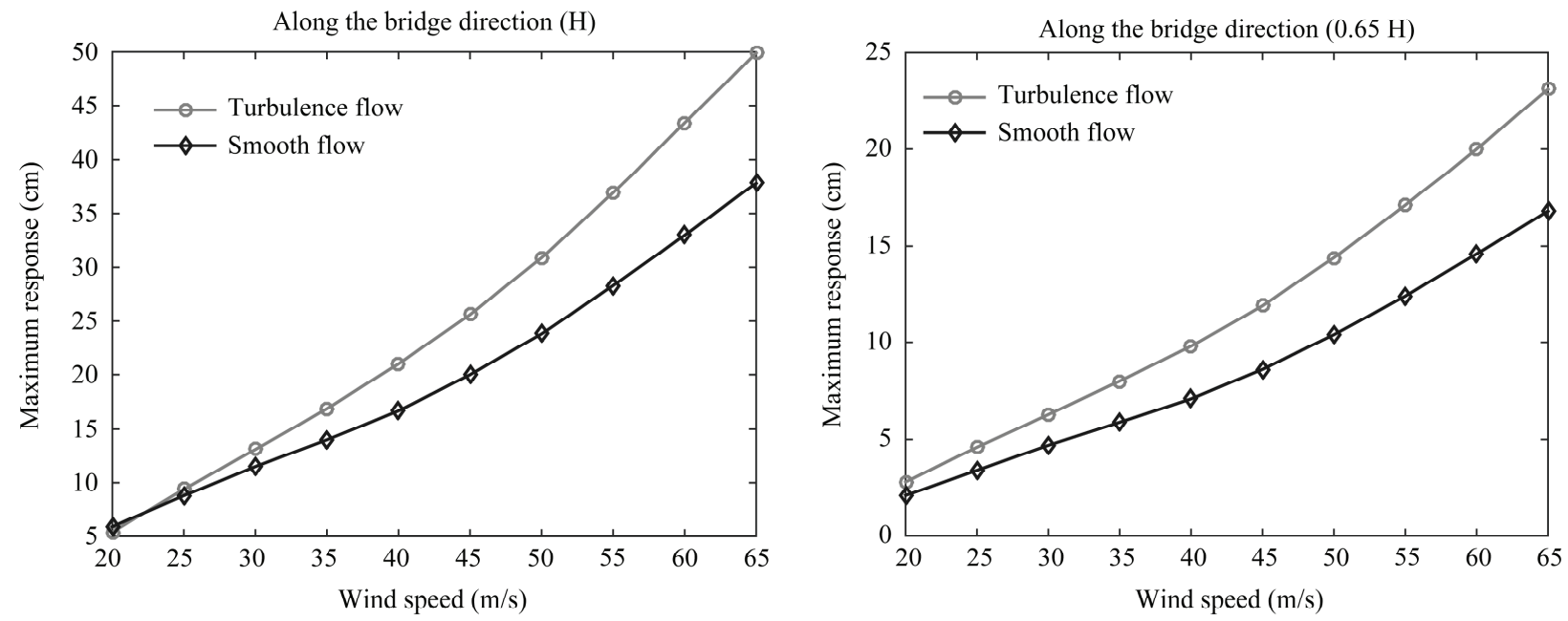

Figure 7. The responses of the bridge tower in the along the bridge direction under different flow conditions.
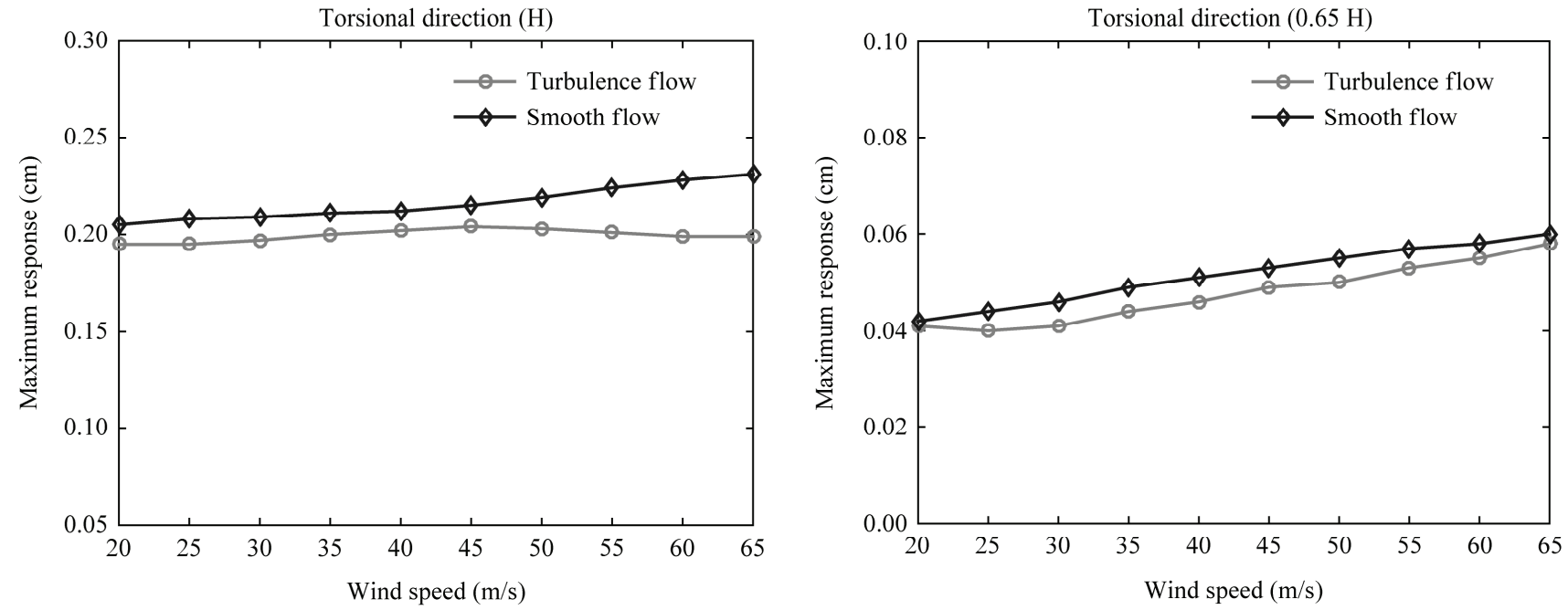

Figure 8. The responses of the bridge tower in the torsional direction under different flow conditions.
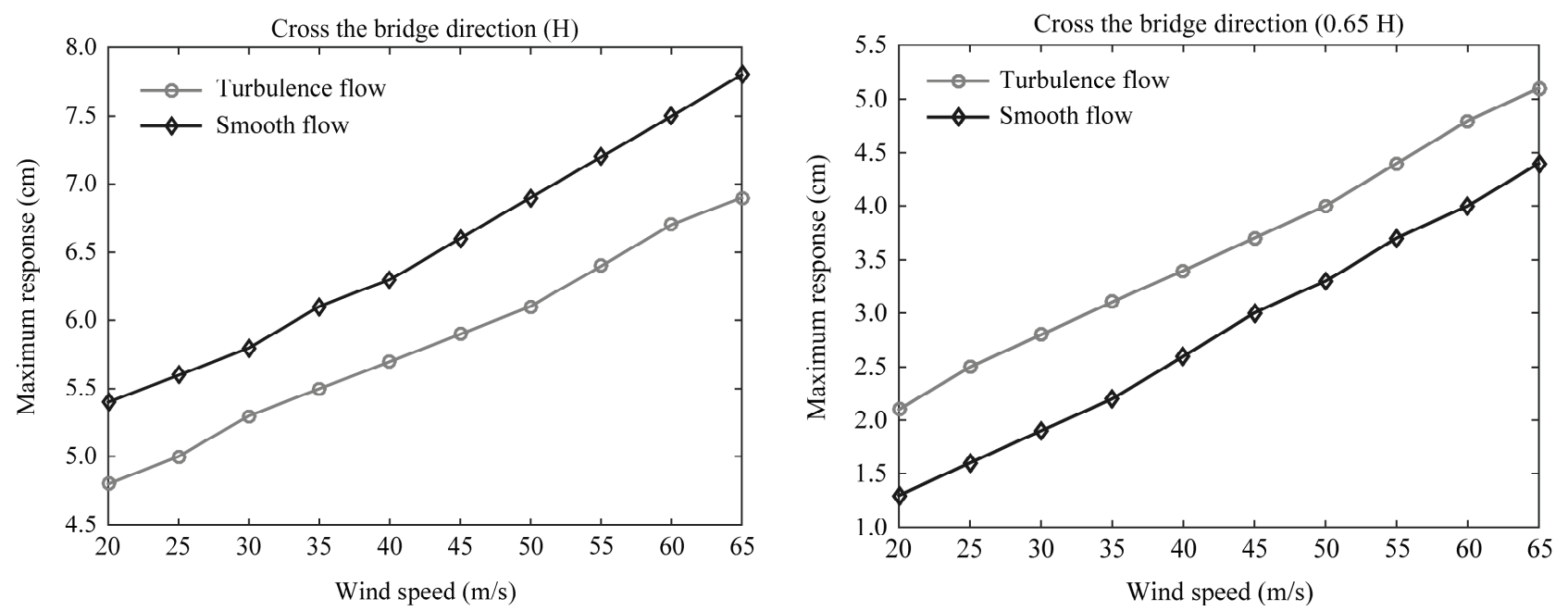

Figure 9. The responses of the bridge tower in the cross the bridge direction under different flow conditions. 
Table 5

The VIV of the Bridge Tower under Different Flow Conditions and Wind Attack Angles

\begin{tabular}{|l|c|c|c|c|}
\hline Flow Field & $\begin{array}{c}\text { Wind Attack } \\
\text { Angle }\left(^{\circ}\right)\end{array}$ & $\begin{array}{c}\text { Critical Wind Speed } \\
(\mathrm{m} / \mathrm{s})\end{array}$ & $\begin{array}{c}\text { VIV Amplitudes } \\
\left({ }^{\circ}\right)\end{array}$ & Direction \\
\hline \multirow{3}{*}{ Turbulence flow } & 0 & 45 & 0.2969 & Torsional \\
\cline { 2 - 5 } & 5 & 45 & 0.3564 & Torsional \\
\cline { 2 - 5 } & 10 & 45 & 0.3110 & Torsional \\
\cline { 2 - 5 } & 20 & 45 & 0.1626 & Torsional \\
\hline \multirow{3}{*}{ Smooth flow } & 0 & 50 & 0.1920 & Torsional \\
\cline { 2 - 5 } & 5 & 50 & 0.1924 & Torsional \\
\cline { 2 - 5 } & 15 & 50 & 0.1886 & Torsional \\
\hline
\end{tabular}

slender bridge tower. From the aeroelastic test (Section 2.3) and Figs. 7-9, galloping did not occur at the maximum test wind speed of $65 \mathrm{~m} / \mathrm{s}$ under different wind attack angles. This suggests that the bridge tower is not prone to gallop even at relatively high wind speeds. The VIVs of the bridge tower under different flow conditions and wind attack angles are given in Table 5 .

In Table 5, the critical wind speeds under turbulent and smooth flow conditions are $45 \mathrm{~m} / \mathrm{s}$ and $50 \mathrm{~m} / \mathrm{s}$, respectively, which are in close agreement with the design wind speed $49.4 \mathrm{~m} / \mathrm{s}$. The VIVs of the bridge tower are prone to occur at turbulent flow condition and the magnitudes are larger than that under smooth flow condition.

\section{Conclusion}

In this study, the aerodynamic and aeroelastic performance of an irregular bridge tower was investigated through wind tunnel test models. The main conclusions are listed below:

(1) The most unfavourable force coefficient is the lift force coefficient, which occurs at a wind attack angle around $65^{\circ}$.

(2) Turbulence has a great effect on the response of the bridge tower, and it may increase the response significantly. It may also decrease the response of the bridge tower.

(3) The most unfavourable response occurs in the along the bridge direction, and the maximum is $30.95 \mathrm{~cm}$.

(4) The galloping of the bridge tower does not occur even at a high wind speed of $65 \mathrm{~m} / \mathrm{s}$.; he critical VIV wind speeds under different flow conditions are close to the design wind speed of $49.4 \mathrm{~m} / \mathrm{s}$, and turbulent intensity tends to enlarge the VIVs of the bridge tower.

\section{Acknowledgement}

This work described in this paper was partially supported by the Engineering Research Center of Bridge Structure and Material in the Mountainous Area (Chongqing Jiaotong University), Ministry of Education of China (QLGCZX-JJ2015-6,QLGCZX-JJ2015-5); The State Key
Laboratory Breeding Base of Mountain Bridge and Tunnel Engineering (Chongqing Jiaotong University) fund (CQSLBF-Y16-16); The Natural Science Foundation of China under the Grants No. 51278435, 51408087 and the "Xiaoping Science and Technology Innovation Team" fund for Chinese college students.

\section{References}

[1] Z.-S. Chen, J.-t. Zhou, G. Hu, Y. Li, and H. Ma, A novel movable scaffolding system (MSS) for a long-span curved girder bridge, International Journal of Robotics and Automation, 32(2), 2017, 164-175.

[2] F. Xu, J. Hu, X. Wang, and G. Jiang, Helix cable-detecting robot for cable-stayed bridge: design and analysis, International Journal of Robotics and Automation, 29, 2014, 406-414.

[3] F. Cluni, V. Gusella, S. Spence, and G. Bartoli, Wind action on regular and irregular tall buildings: Higher order moment statistical analysis by HFFB and SMPSS measurements, Journal of Wind Engineering and Industrial Aerodynamics, 99, 2011, 682-690.

[4] T. Tschanz and A. Davenport, The base balance technique for the determination of dynamic wind loads, Journal of Wind Engineering and Industrial Aerodynamics, 13, 1983, 429-439.

[5] K. Tse, P. Hitchcock, and K. Kwok, Mode shape linearization for HFBB analysis of wind-excited complex tall buildings, Engineering Structures, 31, 2009, 675-685.

[6] D.W. Boggs and N. Hosoya, Wind-tunnel techniques to address structures with multiple coupled interactions, Proc. of Structures Congress, Washington, DC, 2001, 1-6.

[7] J.D. Holmes and T.K. Tse, International high-frequency base balance benchmark study, Wind and Structures, 18, 2014, 457-471.

[8] K. Tse, P.A. Hitchcock, and K. Kwok, A time domain analysis technique for aerodynamic wind tunnel model studies, Journal of Wind and Engineering, 5, 2008, 1-16.

[9] K.C. Kwok and P.A. Bailey, Aerodynamic devices for tall buildings and structures, Journal of Engineering Mechanics, $113,1987,349-365$.

[10] K. Kwok and W.H. Melbourne, Wind-induced lock-in excitation of tall structures, Journal of the Structural Division, 107, 1981, $57-72$.

[11] C.M. Chan, M. Huang, and K. Kwok, Integrated wind load analysis and stiffness optimization of tall buildings with 3D modes, Engineering Structures, 32, 2010, 1252-1261.

[12] D.C. Vaz, R.A. Almeida, E. Didier, A.P. Urgueira, and A.J. Borges, Improving the aerodynamic performance of Vila-Real Bridge deck-section, Journal of Wind Engineering and Industrial Aerodynamics, 156, 2016, 72-83. 
[13] E. Simiu and R.H. Scanlan, Wind effects on structures: Fundamentals and applications to design, 3rd ed. (New York: John-Wiley and Sons, Inc., 1996).

[14] A.G. Davenport, Wind loads on structures, (Canada, Ottawa: National Research Council, 1960).

[15] K. Kwok and W. Melbourne, Cross-wind response of structures due to displacement dependent lock-in excitation, Proc. the Fifth Int Conf. on Wind Engg., Fort Collins, Colorado, USA, 1979, 699-708.

[16] K. Kwok and W. Melbourne, The effects of freestream turbulence on a galloping square tower, Proc. 6th Aust. Conf. Hydraulics and Fluid. Mech., Univ. of Adelaide, Adelaide, Australia, 1977, 447-450.

[17] K. Kwok and W.H. Melbourne, Freestream turbulence effects on galloping, Journal of the Engineering Mechanics Division, 106, 1980, 273-288.

[18] Y. Xu, D. Sun, J. Ko, and J. Lin, Buffeting analysis of long span bridges: A new algorithm, Computers \& Structures, 68 , 1998, 303-313.

[19] R.D. Blevins, Flow-induced vibration, (New York: Van Nostrand Reinhold Co., 1990).

[20] H. Xiang, W. Bao, A. Chen, Z. Lin, and J. Liu, Windresistant design specification for highway bridges, Ministry of Communications of the People's Republic of China, Beijing, China, 2004.

[21] G. Diana, F. Resta, M. Belloli, and D. Rocchi, On the vortex shedding forcing on suspension bridge deck, Journal of Wind Engineering and Industrial Aerodynamics, 94, 2006, 341-363.

[22] A. Larsen, S. Esdahl, J.E. Andersen, and T. Vejrum, Storebælt suspension bridge-vortex shedding excitation and mitigation by guide vanes, Journal of Wind Engineering and Industrial Aerodynamics, 88, 2000, 283-296.

[23] Z. Zhou, T. Yang, Q. Ding, and Y. Ge, Mechanism on suppression in vortex-induced vibration of bridge deck with long projecting slab with countermeasures, Wind and Structures, 20, 2015, 643-660.

\section{Biographies}

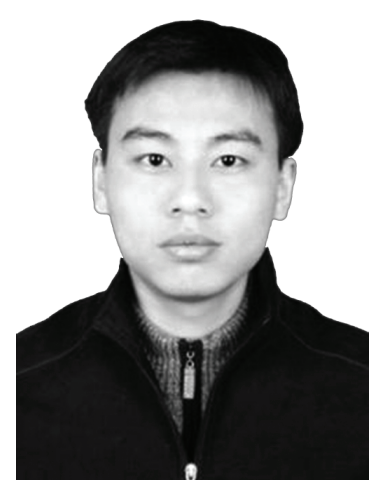

Bin-hua Xia is a chief engineer working in the Hunan Construction Engineering Group Corporation. He is also a Ph.D. candidate majoring in Civil Engineering at the Changsha University of Science and Technology. His research area is reinforced concrete and masonry structure theory and structural reliability theory.

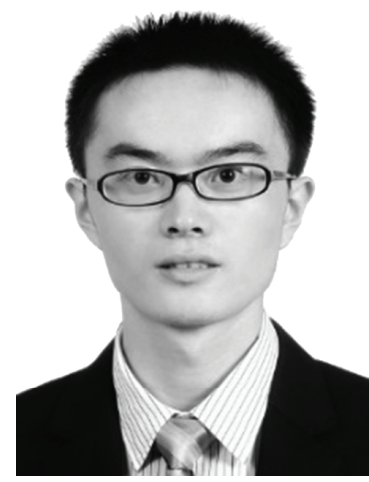

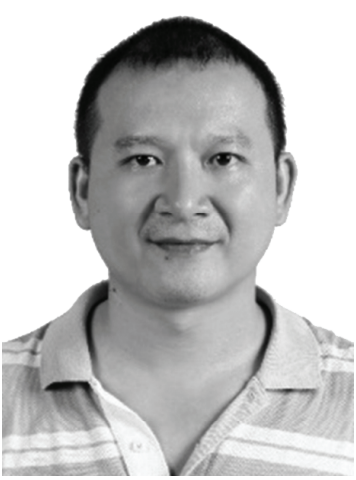

Tian-long $L i$ is a senior engineer and deputy director of Qionghai construction engineering quality and safety supervision station. He is also a Ph.D. candidate majoring in Civil Engineering at the Changsha University of Science and Technology. His research area is reinforced concrete and masonry structure theory and structural reliability theory.

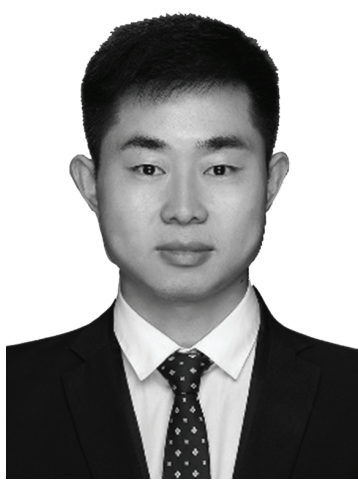

Yong-da Yang is a Ph.D. candidate majoring in Civil Engineering at the Changsha University of Science and Technology. His research area is reinforced concrete and masonry structure theory and structural reliability theory.

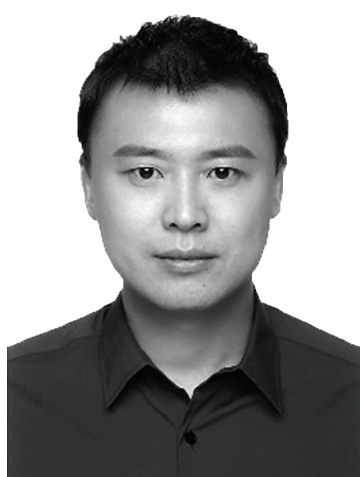

Lei Liu is a senior engineer of China Communications construction company Ltd. He was a project manager of the Hong Kong-Macau-Zhuhai Bridge. His research area is bridge engineering. 